\title{
Understanding the Sharing Economy
}

\author{
Diane Coyle and Shane O'Connor
}

\section{ESCoE Discussion Paper 2019-04}

February 2019 
Understanding the Sharing Economy

Diane Coyle and Shane O'Connor

ESCoE Discussion Paper No. 2019-04

February 2019

\begin{abstract}
The sharing economy appears to have been growing rapidly. This paper contributes to the debate about its definition and measurement through an analysis of interviews conducted with UK platforms identifying themselves as part of the sharing economy. We conclude there are common features that enable a sufficiently clear definitional boundary, namely peer-to-peer digital matching and greater utilisation of under-used assets or skills. We find that the larger sharing economy platforms reduce costs and entry barriers for smaller platforms, contributing to a rich ecosystem. This implies a useful definition should include business-to-business peer-matching transactions, as well as business-to-consumer transactions. In addition to their economic impacts transactions that would not otherwise occur, lower consumer prices and additional choice, the scope to earn additional income in a flexible manner, and the greater use of assets with spare capacity - all the interviewees expressed overt non-financial motivations, such as positive environmental impact, contributing to the community, and building trust. We argue this common intrinsic motivation means measurement of the sharing economy for some purposes should also include those platforms which enable free rather than monetary exchanges.
\end{abstract}

Keywords: Sharing economy, digital platforms

JEL classification: D16, D26, L22

Diane Coyle, University of Cambridge \& ESCoE, dc700@cam.ac.uk. Shane O’Connor, Office for National Statistics, shane.o'connor@ons.gov.uk.

Published by:

Economic Statistics Centre of Excellence

National Institute of Economic and Social Research

2 Dean Trench St

London SW1P 3HE

United Kingdom

www.escoe.ac.uk

ESCoE Discussion Papers describe research in progress by the author(s) and are published to elicit comments and to further debate. Any views expressed are solely those of the author(s) and so cannot be taken to represent those of the ESCoE, its partner institutions or the Office for National Statistics (ONS).

(C) Diane Coyle and Shane O'Connor 


\title{
UNDERSTANDING THE SHARING ECONOMY
}

\author{
Diane Coyle and Shane O'Connor ${ }^{1}$
}

\section{Abstract}

The sharing economy appears to have been growing rapidly. This paper contributes to the debate about its definition and measurement through an analysis of interviews conducted with UK platforms identifying themselves as part of the sharing economy. We conclude there are common features that enable a sufficiently clear definitional boundary, namely peer-topeer digital matching and greater utilisation of under-used assets or skills. We find that the larger sharing economy platforms reduce costs and entry barriers for smaller platforms, contributing to a rich ecosystem. This implies a useful definition should include business-tobusiness peer-matching transactions, as well as business-to-consumer transactions. In addition to their economic impacts - transactions that would not otherwise occur, lower consumer prices and additional choice, the scope to earn additional income in a flexible manner, and the greater use of assets with spare capacity - all the interviewees expressed overt non-financial motivations, such as positive environmental impact, contributing to the community, and building trust. We argue this common intrinsic motivation means measurement of the sharing economy for some purposes should also include those platforms which enable free rather than monetary exchanges.

JEL codes: D16, D26, L22

Keywords: Sharing economy, digital platforms

The term sharing economy came into widespread use less than a decade ago, referring to a rapidly-growing number of digital platforms with a business model significantly enabled by increasing broadband internet access and smartphones, and often with a specific social motivation. The phenomenon was sufficiently striking that it has led to a number of attempts to estimate its growth and scale, and also to calls for statistical agencies to provide better measures of the sharing economy. This demand for a better understanding sits in the context of a wider debate about the measurement and economic impact of the digital economy. In addition, a debate has emerged about the appropriate regulation of sharing economy platforms, as a handful have grown to significant scale in their markets, with disruptive effects on incumbents.

However, there is no consensus definition of the sharing economy. Understanding the business models of the relevant platforms may help with definition and measurement. This

\footnotetext{
${ }^{1}$ University of Cambridge \& ESCoE, and Office for National Statistics, respectively. The views expressed here are those of the authors alone. We are grateful to ONS and ESCoE colleagues for their helpful comments, and to two anonymous reviewers for theirs.dc700@cam.ac.uk
} 
study contributes to this through an analysis of semi-structured interviews with UK sharing economy platforms. We conclude:

- There are common features that enable a sufficiently clear definition of the sharing economy, namely peer-to-peer digital matching and greater utilisation of under-used assets or skills, characterising both profit and non-profit platforms, and including businesss-to-business as well as business-to-consumer transactions. This points to a different definition from that developed by the Office for National Statistics for national accounts purposes;

- There is an increasingly rich ecosystem of platforms, with big platforms providing services which significantly lower costs and entry barriers for start-ups, particularly by reducing the transactions costs involved in satisfying regulatory requirements;

- Finally, all the sharing economy businesses taking part in the interviews express strong non-financial motivations, such as positive environmental impact, contributing to the community, and building trust, and there is continuity between the non-profit and for-profit segments in terms of intrinsic motivation.

We first discuss the importance of the sharing economy phenomenon in the context of analysis of the digital transformation of the economy. We describe our methodology and set out some key features of the organisations we interviewed. After discussing our findings, we turn to the economic impact of the sharing economy, and the implications for definition and measurement.

\section{Context}

The term 'sharing economy' has come into widespread use relatively recently, reflecting the phenomenon of a growing number of business and non-profit entities that describe themselves in this way. However, not only is there no consensus definition other, overlapping, terms are also used, such as collaborative consumption or the gig economy. It is a phenomenon that provokes strong reactions, as Codagnone and Martens (2016) highlight, many negative, as some commentators insist it should involve a pro-social rather than for-profit motivation. Different agencies offer varying definitions, meaning that classification and measurement vary also.

The growth of the sharing economy appears to have been quite rapid, albeit some of this growth will represent substitution away from other economic activities, driving a demand for official statistics to capture the phenomenon better. For example, in the UK ONS (2016a) reported a significant increase in the number of sharing economy businesses. Most had been created since 2012 and were showing growth in turnover and employment (Figure 1). PriceWaterhouseCoopers (2014) forecast that the sharing economy would be worth $f 9$ billion to the UK economy by 2025, up from $£ 0.5$ billion. Coyle (2016) drew on a survey of members of Sharing Economy UK (SEUK), the sector trade body, and other sources to estimate that a large number of individuals had participated to some degree in the sharing 
economy, either as users or suppliers, suggesting that $3 \%$ of the UK workforce (equivalent to around 1 million people) had provided a sharing economy service. This is similar to estimates for the overlapping categories of gig economy work, zero hours contracts and agency work in the Taylor Review (2016). Coyle highlighted that welfare gains arising from matching platforms are not included in GDP while the deflator used to calculate real GDP omitted the lower prices consumers were able to pay via the platforms. In a survey of internet use ONS (2018) found that $22 \%$ of all adults had used accommodation platforms in the sharing economy and $10 \%$ had used ridesharing platforms (excluding Uber), with greater usage by the 25-44 age group. The Bean Review (2016) argued in general for better measurement of the digital economy, including new platform models. The drive to understand and measure better the sharing economy should be seen in the context of the wider debate about digitalisation of the economy, and its implications for the collection and interpretation of statistics (Coyle 2015, 2017).

Figure 1: Sharing economy businesses' employment and turnover with cumulative business establishments

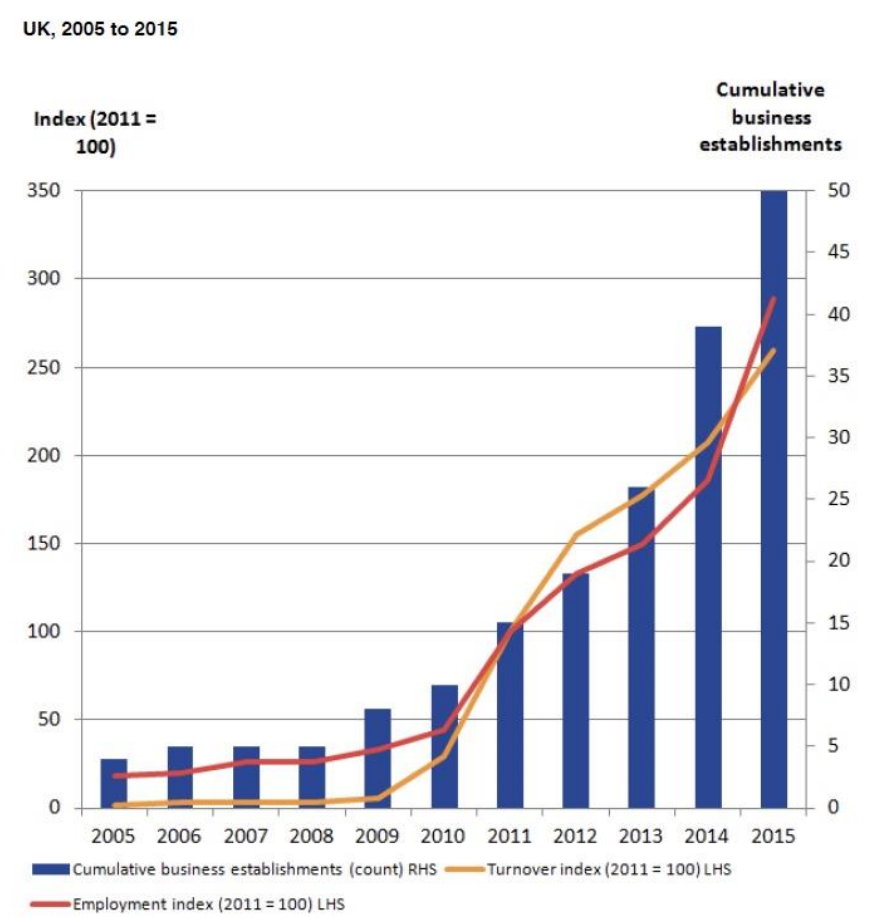

Source: ONS (2016a)

The growth illustrated by Figure 1 prompted a policy response in the UK. The Wosskow Report (2014) argued for industry and policy measures to encourage the growth of the sector, and for a review of regulatory and tax policies applied to sharing economy activities. The March 2016 UK Budget introduced a $£ 1000$ tax allowance for individuals supplying accommodation or services as sharing economy 'microentrepreneurs'. At the same time, in a number of countries and cities, authorities have grown concerned about the impact of 
some sharing economy platforms in terms of either the failure to comply with local regulations or adverse effects such as congestion or crowding out locals, while incumbents in some cases have protested about the competition. Such issues make measurement of the sharing economy desirable for the sake of well-informed analysis and regulation.

ONS (2016a) outlined some of the measurement challenges faced by NSIs (lack of an agreed terminological definition, noting the fact that individuals are participating in large numbers and that many transactions are not monetary). ONS (2016b) highlighted progress made to date, including greater definitional clarity, further scoping activities using the InterDepartmental Business Register (IDBR) and describing the challenges presented by the administrative and new 'big data' avenues for data collection.

\section{Issues in defining and analysing the sharing economy}

Some large sharing economy businesses such as Airbnb, Taskrabbit and Gumtree have become familiar parts of the consumer landscape. However, as noted, there are several possible approaches to defining the sharing economy, with alternative terms including 'access-based consumption' (Bardhi and Eckhardt 2012), 'collaborative consumption' (Belk 2014), and 'connected consumption' (Schor 2014, Schor and Fitzmaurice 2015).

Botsman (Botsman and Rogers 2010, Botsman 2015, 2017) argues that different terms should be consistently used for different business types. She classifies these as: the collaborative economy (decentralised markets, for example Etsy), the sharing economy (sharing underused assets, for example Airbnb); collaborative consumption (updating traditional business models such as car hire, for example Zipcar); and on-demand services (for example Uber).

Schor and Fitzmaurice (2015) suggest the term 'sharing' is applicable only to businesses such as Crowdsurfing and Freecycle, which do not involve monetary transactions.

The US Department of Commerce (Telles Jr. 2016) prefers the terminology 'digital-matching firms'; this narrower focus highlights key traits as well as monetary transactions: the use of IT to facilitate peer-to-peer transactions, use of user-based ratings system as the main quality control method, flexibility in working hours for workers on the platforms and workers having their own assets or tools.

Stokes et al. (2014), use the term 'collaborative economy', categorising businesses and ventures under four pillars: collaborative consumption (gaining access to goods or services through means including renting and bartering, for example Zipcar), collaborative production (working together to design products or services, for example OpenStreetMap), collaborative learning (open-access learning courses or experiences, for example Wikipedia) and collaborative finance (finance outside of traditional schemes, for example 
Crowdfunder). They further sub-divide these pillars and identify key traits, including the use of the internet and trust-based interaction (2014: 13).

In their survey, Codagnone and Martens (2016) offer a broad definitional matrix in order to map different sharing economy businesses. They agree, however, that much of the terminological debate results in definitions that are ostensive (definitions that rely on examples to illustrate the meaning) rather than intensional or connotative (definitions that provide necessary and sufficient conditions for attribution) in nature.

This brief survey makes it clear there is no agreement even about the relevant dimensions of a definition. Nevertheless, the term sharing economy is in widespread use. For their part, industry insiders (Stephany 2015) also use the term sharing economy, as does the UK trade body, SEUK, while it is also used in many governmental and official documents (OECD 2016, Codagnone and Martens 2016). ONS defines the concept as: "The sharing of under-used assets through completing peer-to-peer transactions that are only viable through digital intermediation, allowing parties to benefit from usage outside of the primary use of that asset." We will use the term sharing economy throughout this paper, returning to the question of definition after discussing our findings.

\section{Measurement of the sharing economy: progress to date}

There has been relatively little official measurement or analysis of the sharing economy to date, although this is beginning to change. For example, EU countries have been adding relevant questions to the Internet Use surveys. In its exploratory work, ONS (2016a,b) identified three categories: property rental and access; peer-to-peer services; and peer-topeer finance. It stated the intention to introduce questions into existing surveys to increase data on employment and revenues, as preliminary efforts to use big data techniques faced continuing challenges, both legal and technical. The European Commission (2018) defines four categories: accommodation, transport, skills and finance. In a report proposing a measurement methodology, it estimated that the size of what it termed the 'collaborative economy' amounted to $0.17 \%$ of EU GDP in 2016 , with 394,000 people $(0.15 \%$ of the workforce) engaged in it.

Outside Europe, Statistics Canada (2017) recently published data from their Labour Force Survey conducted in October 2016. Seven specific questions were posed regarding the sharing economy, focusing on peer-to-peer transportation services and private accommodation services. They found that $9.5 \%$ of the Canadian population aged 18 and over had used either transportation or accommodation services during the period November 2015 to October 2016, with estimated spending totalling C\$1.31 billion (Statistics Canada 2017). The survey also asked whether respondents had offered sharing services, reporting a much smaller figure ( $0.2 \%$ for accommodation and $0.3 \%$ for transportation). 
Much official work has been limited to reviews. In the US, the Department of Commerce Economic and Statistics Administration (Telles Jr. 2016) considered what it named 'digital matching firms'. While not presenting any new figures, from its overview of other reports (including PricewaterhouseCoopers 2014 and Olsen and Kemp 2015) it concluded that, although rapidly expanding, they currently represent a small part of the US economy. The Organisation for Economic Co-operation and Development (OECD) has established a Working Party on Measurement and Analysis of the Digital Economy. An initial literature review (2016) reported data from sharing economy businesses themselves (including Airbnb and Uber). In France, the National Institute of Statistics and Economic Studies (Insée) explored (Bellégo and Mahieu 2016) the 'collaborative economy', outlining what would and would not be considered part of it. However, it did not reach any conclusions concerning the scale of its impact on the wider French economy.

A number of analysts have also published estimates of the sharing economy. A recent report by the JP Morgan Chase Institute using data from customer transactions found that the fraction of their customer sample earning income from one of the platforms increased from only 0.3 percent of the sample in the first quarter of 2013 to 1.6 percent in the first quarter of 2018.

The transportation sector dominated in this growth. The report estimated that as of March $2018,4.5 \%$ of the families in the sample had participated in the platform economy over the previous year. Previous research by the Institute had found that as of June 2016 , over $4 \%$ of a sample of 5.6 million checking account holders had obtained income through at least one of 42 online platforms since October 2012.

\section{Methodology}

Our study aimed to understand the distinctive considerations, motivations and characteristics of businesses that described themselves as being part of the sharing economy. In order to explore them in an open-ended manner, albeit informed by earlier research, we adopted a qualitative, semi-structured interview methodology (Saunders, Lewis and Thornhill 2009), using the same interview guide in each case.

The participants were found by approaching members of the SEUK, the industry trade body. Clearly, this was a self-selecting group and being members of this body means interview participants identify themselves as being in the sharing economy. We did not apply additional filters, considering this self-identification to be appropriate for our aims, as the interviews specifically aimed to explore the self-identification and definitional issues. We asked all SEUK members if they would consider being interviewed, and undertook some purposive selection (Easterby-Smith et al. 2008) in order to have a spread across different vertical sectors and size bands. In total, we interviewed face-to-face founders or senior 
managers in 12 businesses. ${ }^{2}$ Most participants volunteered their motivation as being the desire to have the sharing economy better understood, particularly in order to contribute to a well-informed public policy debate about regulatory issues. ${ }^{3}$ A sense of their frustration that public debate is dominated by negative media coverage concerning a handful of large platforms was palpable, and perhaps helps explain interviewees' willingness to take part. As one interviewee put it: "Many get a misreading of what we offer because they get a Daily Mail horror story. I need to be able to talk to government stakeholders, consumers and the media about the value of us as a platform, but also the value of us as an industry."

We additionally collected some initial information from company websites. The interviewees are described in Table 1 . They cover several vertical sectors, and company sizes ranging from small start-ups to UK operations of large global companies. The interviews were conducted in February-April 2018.

Table 1: Businesses interviewed

\begin{tabular}{|c|c|c|c|c|c|}
\hline Company & $\begin{array}{l}\text { UK } \\
\text { launch }\end{array}$ & Main sector & $\begin{array}{l}\text { Number } \\
\text { permanent } \\
\text { staff in UK }\end{array}$ & Initial funding & Gender of interviewee(s) \\
\hline Airbnb & $\begin{array}{l}2011 \\
(2008 \\
\text { globally) }\end{array}$ & $\begin{array}{l}\text { Short-term } \\
\text { accommodation }\end{array}$ & 75 & Parent company & $M$ \\
\hline Airsorted & 2015 & $\begin{array}{l}\text { Short-term } \\
\text { accommodation }\end{array}$ & $65-70$ & $\begin{array}{l}\text { Personal loan, } \\
\text { followed by early } \\
\text { stage investment }\end{array}$ & $M$ \\
\hline EasyCar Club & 2013 & Car sharing & 15 & Parent company & $M+M$ \\
\hline Gumtree & 2000 & $\begin{array}{l}\text { Classifieds esp } \\
\text { goods, cars, jobs }\end{array}$ & $180-190$ & $\begin{array}{l}\text { Individual } \\
\text { investment and } \\
\text { organic growth. } \\
\text { Bought by eBay } 2005\end{array}$ & $M$ \\
\hline Hiyacar & 2016 & Car sharing & 16 & Seedrs crowdfunding & $\mathrm{F}$ \\
\hline Liftshare & 1996 & Ride sharing & 24 & $\begin{array}{l}\text { Individual } \\
\text { investment } \\
\text { organic growth; no } \\
\text { external funding }\end{array}$ & $M$ \\
\hline Omoove & 2001 & $\begin{array}{l}\text { Technology for } \\
\text { car sharing }\end{array}$ & $30-50$ & $\begin{array}{l}\text { Bought by } \\
\text { Octotelematics } 2012\end{array}$ & $M$ \\
\hline
\end{tabular}

\footnotetext{
${ }^{2}$ The number of interviewees is in line with the norm for this studies of this type (Eisenhardt 1989).

${ }^{3}$ No payments were made to any participants.
} 


\begin{tabular}{|c|c|c|c|c|c|}
\hline Patchwork & 2014 & $\begin{array}{l}\text { Crowdfunding } \\
\text { gifts/time }\end{array}$ & 4 & $\begin{array}{l}\text { Group of individual } \\
\text { investors }\end{array}$ & $\mathrm{F}$ \\
\hline Staff Heroes & 2016 & Skills/staffing & 17 & Private funding & $M$ \\
\hline Stripe & 2011 & $\begin{array}{ll}\text { Technology for } \\
\text { payments on } \\
\text { platforms }\end{array}$ & $\begin{array}{l}30 \text { (in UK } \\
\text { office) }\end{array}$ & 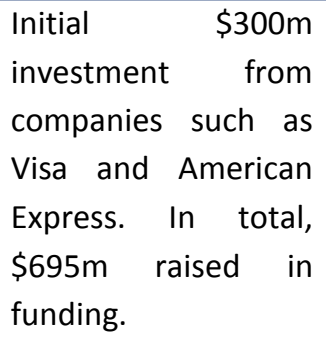 & $M+M$ \\
\hline TaskRabbit & $\begin{array}{l}2013 \\
2008 \text { US, } \\
2013 \text { UK }\end{array}$ & Skills & $80-90$ & $\begin{array}{l}\text { Individual } \\
\text { investment and seed } \\
\text { funding from } \\
\text { venture capitalist } \\
\text { firms. Bought by } \\
\text { IKEA 2017. }\end{array}$ & $\mathrm{F}$ \\
\hline Underthedoormat & 2015 & $\begin{array}{l}\text { Short-term } \\
\text { accommodation }\end{array}$ & 15 & $\begin{array}{l}\text { Internal funding } \\
\text { from board + rounds } \\
\text { of Seedrs } \\
\text { crowdfunding } \\
\text { investment }\end{array}$ & $F+M$ \\
\hline
\end{tabular}

Interviews were conducted February-April 2018, each lasting 60-90 minutes.

The interviews covered the practical operations of the business such as technology choices, marketing, location, number of employees, and understanding the business and financial model; the motivations of the organisation; and the interviewee's understanding of the sharing economy and its impact, including issues such as benefits to suppliers and users, trust/reputation, and wider social and economic impacts. We derived systematic data from the transcribed interviews under headings corresponding to the structure of the questions and informed by our prior analysis of the literature and discussion with SEUK. Other categories of result - notably the character of the link between trust and the regulatory framework, and the complex emerging ecosystem of sharing economy platforms, as described in our findings below - emerged from the data gathering process itself. In the quotations from interviewees below, we characterise them as being in one of three categories: accommodation, transport, and other.

\section{Findings}

\section{Organisation of sharing economy platforms}

\section{Location}


Most of the businesses were London-based, with some beginning to or considering expanding from London to other dense urban locations such as Manchester or Edinburgh. This is natural in the sense that London accounts for a large share of the UK economy in general. There were also two specific, related reasons given for the choice: one that the scope for matching suppliers and users depends on sufficient numbers of reasonably closely co-located participants on both sides of the platform; the other that the viable scale of operation requires a minimum number of transactions across the platform and so the sooner the number of transactions reaches that point, the better the chances of success. This makes the sharing economy a phenomenon of large urban agglomerations.

"You need a certain number of homes and a number of year-round visits, to be able to carry the constant infrastructure you have to have to provide our service. That's why it's a model best suited to major cities like London." (Accommodation)

"In London ... there is a large number of young professionals who would not see the value in owning a car. ... we found that going away for the weekend to see friends and family is the number one usage." (Transport)

The longer-established and larger platforms in our group reported that they are starting to expand in cities outside London, such as Bristol, Birmingham and Manchester. For example, Airbnb has reported that growth in its earlier markets such as London is slowing while supply of accommodation offered outside cities is growing rapidly. Another, Liftshare, already has a widely geographically dispersed user base because of the character of the platform, which provides ride sharing for commuters as well as more occasional journeys.

\section{Funding}

In our sample, there were two types of investment: either by a parent company or start-up funding. The latter consisted either of classic modes such as personal funds and loans, or angel investors, or - for a sub-set - crowd-funding through the platform Seedrs. In addition, a number of founders had worked for no pay for some time.

"It's been bootstrapped all the way." (Transport)

The amounts involved for the smaller entities ranged from a few thousand to a few million pounds. Digital platform businesses are not initially very capital intensive, but a number of interviewees said technology costs scale quickly with the number of users.

\section{Technology}

A small minority of the interviewees said they purchased software or outsourced software development, or had done so to begin with. Most considered development of their proprietary platform software a core capability. Those which had started with outsourced technology brought it in-house when they were able; the trade-off is a higher cost of paying external providers against the management time and need for relevant skills of the staff. In the UK, there is a shortage of skilled IT professionals (NAO 2018). So some of our sample 
employed engineers overseas, for access to skills rather than to reduce costs. For the majority, when asked about the structure of their costs, technology was named as one of the biggest cost elements, whether paying either for outsourced technology or their own software engineers and other technology costs (such as payments to cloud platforms).

"You focus on using technology to scale. ... It's about automating processes, modularising the architecture so you can add things, and enriching customer experience." (Accommodation)

"The software is continuously developed and improved." (Other)

"A lot of our work is R\&D and we are pushing the boundaries all the time." (Transport)

Relevant to the measurement of R\&D and investment in the sharing economy (and digital businesses more generally), payment of the salaries of engineers or payment for outsourced software development were widely spoken of as part of the businesses' investment expenditure. In the construction of national accounts aggregates such as business investment and GDP, these are correctly included as R\&D or investment in software if identified as such by survey respondents; to the extent that the businesses do not report them in the appropriate categories, they would be classed as intermediate costs and netted off value added.

\section{Marketing}

Marketing was cited as another big cost element by more than half of the interviewees. The majority paid for some external marketing, mainly online. This means Google and Facebook, who act as gatekeepers given their share of the online advertising market. Search engine optimisation and changes in the ranking algorithm can make a big difference to marketing outcomes. Some of the smaller interviewees, at the start up end of the scale in terms of size, said they focus more on social media to create buzz (Campbell et al 2017). A small number said they advertise on the London Underground.

"Changes to Google algorithms pushed us down the rankings for some high volume generic search terms and this has affected our traffic." (Transport)

"There's a duopoly of how you can reach customers. ... The cost for Facebook and Google is just going up because they have a duopoly and they can do whatever they want." (Other)

However, many - from smallest to largest - also said word-of-mouth was important, including for reasons of community-building and trust: knowing somebody who had experience of a novel kind of service helps potential users overcome some of their hesitations.

"We know that 26\% of people who register say they've been recommended by friends, so that's very strong word of mouth recommendation." (Other) 


\section{Pricing and business model}

The interviewees use a range of different pricing structures. Their reported dimensions of choice in setting prices are:

- For per transaction commissions or fees, how much should they be, and applied to which side of the platform - suppliers or users. The commission range in our sample was $3 \%$ to $30 \%$. More often than not, just one side of the platform (suppliers) paid the commission, but this varied;

- Whether to have a suggested rate card or indicate other asking prices to suppliers on the platform - or alternatively to allow significant customisation or individual price setting. Regulatory issues are relevant to this choice. Some were wary of falling foul of competition rules against price co-ordination, while minimum wage legislation was an issue for skills platforms, which considered a suggested rate card a way of guarding against hourly wage rates that were too low;

- Whether to implement any kind of surge pricing or demand management;

- Whether to distinguish user groups by offering a free service to some categories of user but charging for professional uses.

Some of the platforms offer additional paid for services (such as optional insurance packages, or cleaning and concierge services) but these charges are typically passed straight through to the relevant providers.

In the case of the larger interviewees, revenues are also derived from selling software licences or software as a service. This relates to the finding that there is an increasingly complex platform ecosystem, as discussed below.

\section{Market dynamics and the platform ecosystem}

A common theme was the importance of achieving a minimum profitable scale, and the scope for scaling up very quickly once that point has been reached.

"We are growing pretty fast. It took 18 months to get the first thousand hires, and it's been exponential since then." (Transport)

This kind of tipping point dynamic has been identified as a characteristic of digital platforms (see for example Evans and Schmalansee 2017). Another common characteristic is the importance of keeping an appropriate balance between suppliers to the platform on one side and users on the other. In some cases, there will be far fewer suppliers than users; for example, there are far fewer hosts than guests on the accommodation platforms. This is characteristic of the sharing economy platforms making use of otherwise unused assets. In other cases, such as the skills platforms, the ratio will be higher.

In general, there was agreement in our sample that it was more challenging to sustain an appropriate number of suppliers, such as hosts or car owners. As one of the transport interviewees explained, the individual car owner takes on the tasks otherwise performed by employees of a car hire company, such as checking and cleaning the vehicle. The same is true of accommodation owners using the short-stay accommodation platforms, although in 
those cases, as the market matures, there is a growing number of providers of ancillary services to take on those tasks, such as cleaning, laundry, key access and so on. In a paper analysing the dynamics of the platforms using its services, Stripe concluded that successful marketplaces (including sharing economy platforms) were distinguished by providing a better experience to sellers, rather than buyers. They found that the fastest-growing platforms had a focus on seller retention from the very first months (Hilger 2018). The cost of onboarding suppliers is higher than user acquisition costs, and the platforms state they devote considerable effort to making the experience a positive one. Thus, in addition to customer service, many referred to their offer to suppliers, with examples including providing training, arranging appropriate insurance, dispute resolution mechanisms between suppliers and users, and assistance or advice in meeting regulatory requirements.

"Getting hosts to host is a significantly heavier lift than getting guests to guest." (Accommodation)

In our sample, there was evidence of a pattern of a widening array of services being offered as sharing economy businesses mature, something which has also been observed more widely with digital platforms. For instance, Airbnb launched services complementary to its core accommodation offer, and recently stated that this part of its business is growing faster even than the accommodation offer in its early days. ${ }^{4}$

The accommodation segment of the sharing economy represented in our sample of interviewees illustrates this maturing ecosystem. Airbnb operates as a platform for smaller platforms such as Underthedoormat and Airsorted. These platforms provide a range of addon services, partnering with laundry services, for instance, and providing insurance. They also themselves act as a platform between accommodation owners and individuals providing services such as cleaning and key exchange. In addition, Airbnb is extending its offer to include a range of travel experiences such as tour guides and restaurants; while conventional travel companies have been acquiring accommodation platforms to be able to offer the different kinds of experience and range of accommodation themselves - for instance, hotel chain Accor purchased the platform Onefinestay. Thus the sharing economy presents itself in this case as a particular form of business model in a rich ecosystem. We return to this below.

"Everyone, when they think of the sharing economy, thinks of the technology and platforms like Airbnb. Our company is as much about logistics because we provide an in-person service. We are changing the operation of hospitality from a centralised hotel with all the rooms in one building, to a disaggregated model with homes across London. That is as big a logistical challenge as it is a technological one." (Accommodation)

\footnotetext{
${ }^{4}$ https://press.airbnb.com/airbnb-doubles-down-on-experiences-expanding-to-1000-destinations-and-addingnew-categories-in-2018/
} 
Similarly, Stripe is a platform serving smaller platforms, providing financial transactions services through a specific sharing economy product so they do not need themselves to overcome the significant, costly regulatory barriers such as Know Your Customer and AntiMoney Laundering (KYC/AML). Not only are there transactions costs for a platform in accepting payments from users, there are even bigger transactions costs, particularly KYC/AML, in paying suppliers. Stripe's systems perform these checks on behalf of the platforms using their platform, and it can also update the identification technology (for instance with biometrics) more readily than individual small platforms would be able to do for themselves: "Navigating regulatory complexity is becoming even more challenging for platforms and sharing economy services ... We give entrepreneurs the commerce infrastructure that was once only available to multinational conglomerates."

The increasing complexity of the sharing economy ecosystem does not seem to be widely appreciated. Much of the public discussion focuses on a handful of large platforms, and focuses on their business-to-consumer side. Our interviews made it clear that there are also many start-ups enabled by the bigger platforms, in a dynamic set of markets. As the sharing economy matures, these start-ups consist not only of the sharing economy matching platforms themselves but also the entire set of ancillary services they create the demand for as they compete and seek to differentiate their offers. There is, in addition to the prominent B-to-C sharing economy, a growing business-to-business sharing economy.

Trust

Every one of the businesses interviewed saw trust as fundamental to the success of the platform, particularly as the business model remains novel to many potential users. However, they take a number of different approaches to trust-building.

Many operate a rating system, a mechanism quite widely explored in the literature on sharing economy platforms. Typically these are two-way, in that both sides of a transaction can rate the other, although the specifics do vary, such as how visible these are to the other side ahead of posting, whether there can be replies, whether they are posted simultaneously, and so on. Other research has found that there is an upward bias in ratings (Luca 2017); one of our interviewees stated: "It is quite binary. People tend to give 5s and 1s." (Transport). Some stated that the length of time a supplier had been on the platform and the number of times their services or asset had been used seemed to be used as a stronger signal of reliability. However, a supplier's rating will typically in part determine their ranking in the platform's search algorithm. Other factors affecting ranking include: how quickly emails are replied to; keeping listing and availability up to date; providing photographs (if relevant).

Ratings are clearly intended to build trust between suppliers and users. In addition to ratings, the sharing economy platforms use several other techniques to address this. Many conduct checks on one or both sides of the platform. For example, transport platforms check driving licences and verify identity on one side, and check or provide vehicle insurance 
and breakdown cover on the other. The checks may involve people having to upload photographs, documentation and, increasingly, biometric identification. In the case of accommodation platforms, there may be visits to check the accommodation and ensure appliances work and have documentation on the one side, and identity checks and insurance cover for hosts on the other. The negotiation of appropriate insurance cover was cited by a majority of the platforms we interviewed as a particular hurdle they had to overcome in the early stages of their business.

The interviews made it clear, though, that there is another aspect of trust or reputation, which must also be in place, namely trust in the platform itself - an online business not located near its users. Here, the regulatory barriers become an asset, as compliance with regulations is evidence that the authorities must know of the platform and engage with it for instance, if an official body is confirming identification documents. In addition, presence on larger and better-known platforms can also help. For instance, if a smaller sharing economy platform is using Stripe or another service such as PayPal, and not handling monetary transactions itself, this also helps this second dimension of trust.

\section{Economic impacts of sharing economy platforms}

\section{Matching/differentiation}

When asked what distinguished the sharing economy from other types of digital business, one of the key features mentioned by all interviewees was the peer-to-peer matching. This is a distinctive economic characteristic: the platforms intermediate a form of supply with few economies of scale, but potentially large matching benefits. As noted in the quotation earlier, it is a highly decentralised supply model. One interviewee (Other) observed that the distinguishing feature of a sharing economy platform is permitting maximum differentiation and therefore non-scalability, whereas other types of digital platform standardise the offer, and thus impose greater restrictions on suppliers, for the sake of scalability.

"A lot of the value [sharing economy platforms] are creating is match making. There's a lot of product differentiation. It's search and matchmaking between exactly the right buyer and exactly the right seller, using algorithms to match them up. There's a huge amount of value created in that." (Other)

"We facilitate a lot of transactions that simply wouldn't happen otherwise." (Other)

Asset use

A second key feature identified by some interviewees is the increased use of assets with spare capacity. For the transport and accommodation platforms, the point is obvious. One interviewee linked the growth in asset-based sharing economy platforms to a reducing ownership of assets, particularly among younger age groups: "I think there is a generally accepted view that there is a shift away from ownership toward access for a number of 
things." The platform's contribution is management of a distributed set of assets with some spare capacity in ways that enables suppliers to earn additional income (see below).

For many of our sample, this aspect is closely related to their expression of strong social and environmental motivations, which - as noted earlier - is seen by some as key to the definition of the sharing economy.

"It's a much more efficient use of space that would otherwise be sitting empty." (Accommodation)

"Ownership is transformed into utilisation. ... If you take all the pros and cons, the sharing model is much more efficient." (Transport)

Prices and choice

Many interviewees said the increased variety and/or lower prices are a major reason their users opt to engage in the sharing economy.

Growing the market

A corollary of the matching aspect, combined with attractive prices and a wide range of choice, means that many sharing economy platforms regard themselves as growing the market. For example, the accommodation platforms make this claim with regard to the short-stay travel market in the context of suggestions that they are simply undercutting hotels through lower regulatory standards. The econometric studies to date (eg. Zervas et al. 2014, Coyle \& Yeung 2016) suggest the negative impact of the growth in sharing economy accommodation platforms on incumbent hotels has been relatively modest, although the increase in numbers of visitors has caused a backlash by residents and authorities in some cities.

Income and agency

Suppliers to the platforms are obviously able to earn additional income, or a combination of higher income and more attractive working conditions.

"This is an opportunity for people to unlock value from something they already have." (Accommodation)

Several also emphasised the flexibility and agency provided to suppliers by the opportunity to participate.

"We have people who go away frequently, or who want to spend half the year somewhere else, or don't want to leave their home sitting empty for months at a time. All of a sudden an asset becomes an opportunity rather than a burden." (Accommodation)

"On the host side, earning money is by far the number one motivator. Once people start hosting, though, they say that ... they also enjoy the satisfaction of meeting new people. 
They are suddenly interested again in the local coffee shops and the restaurants because they want to make recommendations to their guests." (Accommodation)

"We make housing more affordable because people are able to generate some extra income to cover an incredible sunk cost." (Accommodation)

\section{Social /environmental}

Although only one organisation in our sample was a social enterprise, every interviewee emphasised the non-monetary benefits provided by the sharing economy. These sometimes alluded to the benefits such as a greater agency accruing to individual suppliers, as described above. Other benefits described were community-building or the delivery of authentic experiences of human relationships in the context of economic transactions; and environmental benefits. Critics of the sharing economy are sceptical of such claims, seeing the business concerned as exploitative ('the gig economy' is often referred to) or seeking to take advantage of regulatory arbitrage (for example, Eckhard \& Bardi 2015, Slee 2016); and even if one is not a sceptic, the aims may not be realised in practice. Nevertheless, the fundamental economic characteristic of peer-to-peer matching, where in many cases the individuals participating in the transaction meet or communicate with each other, means that there is a reduction in the anonymity involved in most types of market transaction in the economy.

"Our business model is set up to take homes that would otherwise be empty and enable guests to stay in them, which is good for the homeowner, it is good for local shops and businesses, and it is good for communities as long as it is managed well." (Accommodation)

"I think we're creating much more authentic experiences." (Accommodation)

"The sharing economy and its platforms like ours are bringing transparency and making it [the job market] a lot more democratic and fair." (Other)

"It is all about that peer to peer community spirit, and that's something we're really fostering. ... We host events where we invite our members ... Communities used to share everything before industrialisation, so it's almost like we're going back to basics." (Transport)

As for asset use and reduced environmental impact thanks to the more intensive use of existing assets, this seems a valid claim compared to a counterfactual of sharing economy users otherwise buying the assets. It may also be that they, for example, make more journeys than they otherwise would, or substitute sharing economy rentals for other rentals.

"The thing I care most about is how many people we help to start sharing". ... "The typical member who shares their car will save $f 1,000$ a year on travel costs. ... Environmentally they are cutting their carbon footprint by 10\%." (Transport) 
"I think people are reaching peak stuff. ... You're getting people wanting to define themselves and project their own identity. ... For us it's genuinely reducing the amount of crap that ends up in landfill." (Other)

\section{Definition and measurement}

Asked about the definition of the sharing economy, there was a difference between interviewees and the ONS definition quoted above. Our interviewees agreed with the ONS in broad terms but differed in a number of important respects. Based on the interviews, the sharing economy platforms would include human capital as an asset - for the skills platforms are firmly seen as being in the sharing economy - and business-to-business transactions. The ONS decision tree applies to transactions rather than entities. It identifies three categories, accommodation, peer-to-peer services, and collaborative finance. Transactions on both transport and labour-intensive services platforms could fit into the second category. However, the ONS definition excludes business-to-business transactions, yet our interviews reveal that smaller platforms also transact via larger platforms and this activity is seen by members as an inherent part of the sharing economy ecosystem. This difference raises the issue of the purpose of definition and measurement. For national accounts purposes, the business-to-customer transactions alone are relevant to ensure all relevant transactions in final demand are captured. For any other purpose, however, the broader definition of the sharing economy is appropriate given our finding about the important business-to-business as well as business-to-consumer activities of some of the platforms.

The ONS definition excludes transactions that transfer the ownership of assets, and thus excludes digital platforms enabling the sale of goods, such as Etsy or Amazon Marketplace, or free exchanges of goods, such as Freecycle or Olio. Some commentators would include these in a definition of the phenomenon. However, our interviewees agreed transfer of ownership did make these meaningfully different from the sharing economy.

ONS excludes non-profit platforms from its definition, as economic measurement for national accounts purposes includes only monetary transactions; some interview participants considered non-monetary sharing ought to be included. As discussed above, the intrinsic motivations for sharing were expressed by for-profit platforms as well; a full understanding of the phenomenon makes it desirable to measure non-monetary sharing economy activities although these are possibly small scale.

However, interestingly there was disagreement among our interviewees about the need for a tight definition at all, even though all had joined SEUK. One described the sharing economy as a business model rather than a sector of interest in its own right, suggesting conventional sector classification would be appropriate as long as sharing economy businesses were included in statistical samples - for instance, to measure price indices correctly. 
"The sharing economy is traditional business with technology applied." (Other)

On the other hand, others considered that it was important to pin down a definition as the sharing economy is distinctive, in their view, and is creating economic and social value in ways conventional businesses do not.

"There's an identity crisis that we haven't nailed about how do we define ourselves as a sector." (Other)

"There is definitely something going on in the world here. The notion of non-professional participation in the economy generating income from stuff that never used to generate any.... That's definitely something new." (Accommodation)

\section{Discussion}

Codagnone et al. (2016: 20) report as one of their findings the significant confusion of labelling in the domain under consideration here. Confusion and overlap makes for a rich analysis, including of the normative questions about the sharing economy, but are not helpful when it comes to economic measurement and analysis. Statistics have to be constructed on the basis of specific judgments and classifications. In its most recent update, ONS (2017) reported the addition of questions to some existing surveys in order to capture better activity in the sharing economy. Its definition, cited above, and the associated decision tree for the classification of businesses correspond to some key economic features identified by our interviewees, and locate the sharing economy reasonably specifically in the universe of other types of business (Figure 2). Both the peer-to-peer character of transactions, mediated through a digital matching platform, and the efficient use of assets that would not otherwise be fully utilised, are key to the distinctiveness of the sharing economy.

Figure 2: The sharing economy in relation to other categories of business

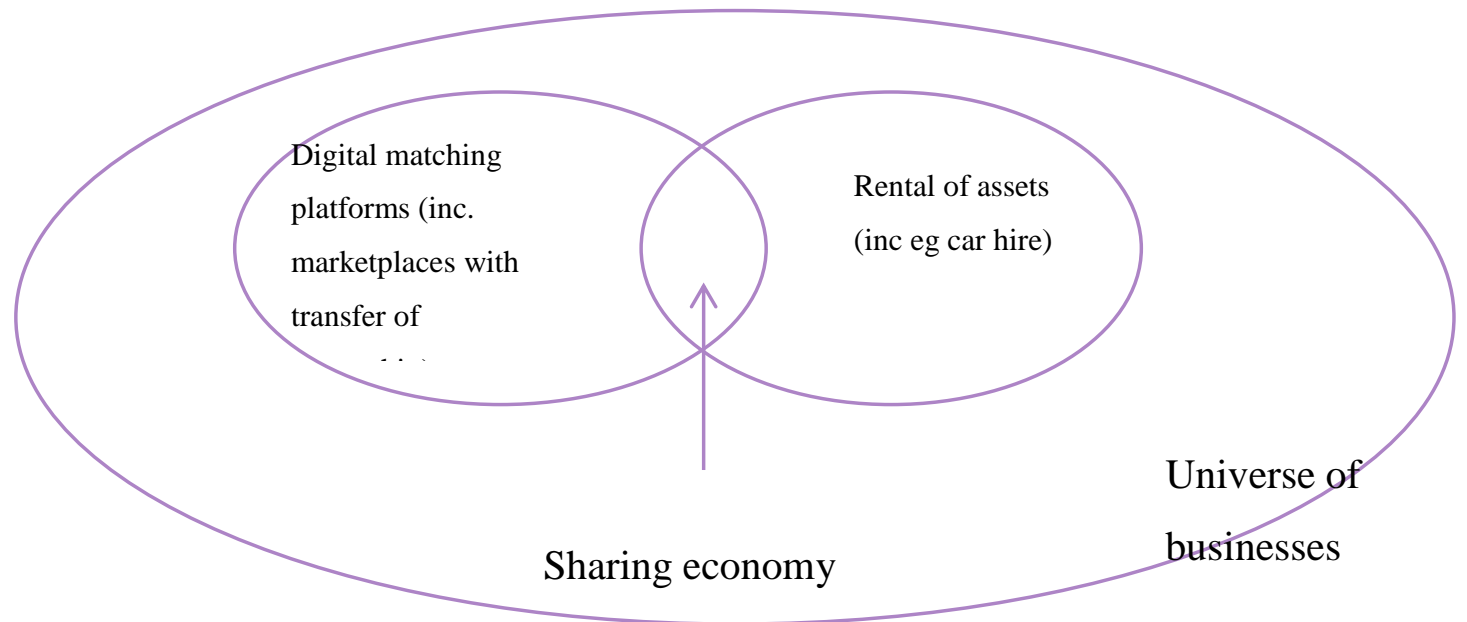


This does not entirely address all definitional questions. One issue, as noted, is the inclusion of business to business transactions. Another is the overlap between sharing economy platforms and other digital platforms, perhaps seen as not genuinely performing the peerto-peer function. Uber is an example, being a private hire taxi business in the UK, an not part of the sharing economy. Some may be seen as exploitative, referred to as the 'gig economy', in the case of employment platforms. This is all the more so because of the highprofile regulatory issues some digital businesses have encountered, and indeed the fact that the main sharing economy categories are in sectors that could be characterised as experiencing regulatory arbitrage (finance, taxis, hotels).

The stated social and environmental motivations of sharing economy entrepreneurs need to be acknowledged; their conventional competitors rarely express similar motivations as being at the heart of their business model. As noted, every one of our interviewees stressed their non-economic impacts. In addition, consumer research has found that users of sharing economy platforms are frequently motivated by issues of sustainability or meaning as well as economic considerations such as low prices or convenience (Codagone et al. 2016, Hamari et al. 2016).

Similarly, although the collection of economic statistics focuses on monetary transactions, for understandable reasons, a full analysis of the phenomenon requires information about non-monetary transactions and benefits. One way to understand this better would be to supplement routine statistical surveys with an extended time use survey, exploring how people use the sharing economy platforms, among other digitally-enabled activities. In any case, empirical assessments of the conventional economic impacts including prices paid for relevant services, income earned by suppliers to the platforms, and volume of activity in relevant markets, require reliable statistics. It is important to be able to demonstrate the benefits of the sharing economy platforms, both in conventional economic terms, as well as in terms of sustainability and well-being, in order to have an informed regulatory debate.

In terms of measuring the size of the sharing economy, the net revenues of the platforms must obviously be distinguished from the far larger value of the transactions flowing through them. Labour market surveys and consumer and price surveys should incorporate questions enabling the identification of services supplied to the platforms (hours per week, earnings) on one side, and purchases and prices paid on the other. One consideration for statisticians is the fact that the platforms consider their investment expenditure to take the form of salaries or fees to software developers, as discussed above, so care is needed to ensure they record the relevant salaries in this way. And they are unlikely to invest in physical capital equipment such as computer servers rather than using cloud computing services, which are regarded as an operating expense and are not yet capitalised (Coyle \& Nguyen 2018).

Finally, the portrait of the rich ecosystem and competitive dynamics of the sharing economy painted by our work is not widely appreciated. Much public and regulatory debate has 
focussed on a small number of large and high profile platforms. Our research demonstrates that large platforms act as platforms for smaller ones, and have significantly reduced transactions costs for starting up a small business. The smaller interviewees in our sample rely on a network of other platforms, to raise finance through crowdfunding, to create a bundle of complementary services, to reduce substantially the regulatory transactions costs, and to get an effective channel to market. It will be important to track these B2B dynamics over time, especially births and deaths of small platforms, how many grow to significant scale, what the net growth in the number of businesses is, and finally the competitive dynamics such as whether there are winner-take-all parts of the sharing economy creating gatekeepers. 


\section{References}

Bardhi, F. and G.M. Eckhardt (2012), 'Access-Based Consumption: The Case of Car Sharing', Journal of Consumer Research, 39(4), 881-898.

Bean, C. (2016), Independent Review of UK Economic Statistics. (London: UK Government). [Available online at: https://www.gov.uk/government/publications/independent-review-ofuk-economic-statistics-final-report, accessed 11/09/2017]

Belk, R. (2014), 'You Are What You Can Access: Sharing and Collaborative Consumption Online', Journal of Business Research, 67(8), 1595-1600.

Bellégo, E. and R. Mahieu, (2016) 'The Role of the Internet in Describing and Analysing the Economy'. (Institut National de la Statistique et Des Études Économiques). [Available online at: https://www.insee.fr/en/statistiques/2496532? sommaire=2496598, accessed 11/09/2017].

Botsman, R. and R. Rogers (2010), What's Mine is Yours: How Collaborative Consumption is Changing the Way we Live. (London: Harper Collins).

Botsman, R. (27 May 2015), 'Defining the Sharing Economy: What is Collaborative Consumption- And What Isn't?', (The Fast Company). [Available online at:

https://www.fastcompany.com/3046119/defining-the-sharing-economy-what-iscollaborative-consumption-and-what-isnt, accessed 14/09/2017].

Botsman, R. (2017), Who Can You Trust? How Technology Brought us Together- And Why it Could Drive us Apart. (London: Penguin).

Campbell, Arthur, Dina Mayzlin and Jiwoong Shin, 'Managing Buzz, RAND Journal of Economics, Spring 2017, 203-229.

Codagnone, C. and B. Martens (2016), 'Scoping the Sharing Economy: Origins, Definitions, Impact and Regulatory Issues', (European Commission JCR Technical Reports: Institute for Prospective Technological Studies, Digital Economy Working Paper 2016/01). [Available online at: https://ec.europa.eu/irc/sites/jrcsh/files/JRC100369.pdf, accessed 11/09/2017].

Codagnone, C. et al. (2016), 'The Passions and the Interests: Unpacking the 'Sharing Economy", (JCR Science for Policy Report, European Commission). [Available online at: https://ec.europa.eu/jrc/en/publication/eur-scientific-and-technical-researchreports/passions-and-interests-unpacking-sharing-economy, accessed 16/8/18].

Coyle, D. (2015), 'Modernising Economic Statistics: why it matters', National Institute Economic Review, 234 (1), F4-F7.

Coyle, D. (2016), 'The Sharing Economy in the UK. SEUK'. [Available online at: http://www.sharingeconomyuk.com/perch/resources/210116thesharingeconomyintheuktp dc.docx1111.docx-2.pdf, accessed 12/09/2017]. 
Coyle, D. (2017), 'Precarious and Productive Work in the Digital Economy', National Institute Economic Review, 240(1), R5-R14.

Coyle, D \& Nguyen, D (2018), Cloud Computing and National Accounting, ESCoE Discussion Paper 2018-19, available at https://www.escoe.ac.uk/research/discussion-papers/.

Easterby-Smith, M., et al.(2008), Management Research (London, UK: Sage).

Eckhardt, G. and Bardhi, F. (2015) 'The Sharing Economy isn't about Sharing at all.' Harvard Business Review. Available online at: https://hbr.org/2015/01/the-sharing-economy-isntabout-sharing-at-all [Accessed 18/09/2017]

Eisenhardt, K. M. (1989), 'Building theories from case study research', Academy of Management Review, 14, 532-550.

European Commission (2018). Directorate-General for Internal Market, Industry, Entrepreneurship and SMEs, Technopolis, Trinomics, VVA Consulting. "Study to monitor the economic development of the collaborative economy at sector level in the 28 EU Member States", https://publications.europa.eu/en/publication-detail/Lpublication/0cc9aab6-7501-11e8-9483-01aa75ed71a1/language-en accessed 12/10/18

Evans, David S. and Schmalensee, Richard, Network Effects: March to the Evidence, Not to the Slogans (2017). Forthcoming, Antitrust Chronicle. Available at SSRN:

https://ssrn.com/abstract=3027691 or http://dx.doi.org/10.2139/ssrn.3027691 Accessed $12 / 1 / 18$

Hamari, J. et al. (2016), 'The Sharing Economy: Why People Participate in Collaborative Consumption', Journal of the Association for Information Science and Technology, 67 (7), 2047-2059.

Hilger, N. (2018), 'How Do Marketplaces Compete? The View From Stripe Connect', [Available at SSRN: https://ssrn.com/abstract=3232470, accessed on 09/10/2018].

Luca, Michael (2017). 'Designing Online Marketplaces: Trust and Reputation Mechanisms'. https://www.hbs.edu/faculty/Publication\%20Files/17-017 ec4ccdc0-4348-4eb9-9f4686e1ac696b4f.pdf Harvard Business School Working Paper 2017-17. Accessed 12/100/18.

J.P. Morgan Chase and Co. Institute (2018), The Online Platform Economy in 2018: Drivers, Workers, Sellers and Lessors:

https://www.jpmorganchase.com/corporate/institute/document/institute-ope-2018.pdf accessed 09/10/2018.

National Audit Office (2018), Delivering STEM skills for the economy.

https://www.nao.org.uk/wp-content/uploads/2018/01/Delivering-STEM-Science-

technology-engineering-and-mathematics-skills-for-the-economy.pdf 
Office for National Statistics (2016a), The Feasibility of Measuring the Sharing Economy. https://www.ons.gov.uk/releases/thefeasibilityofmeasuringthesharingeconomy, accessed 12/09/2017.

Office for National Statistics (2016b), The Feasibility of Measuring the Sharing Economy: Progress Update.

https://www.ons.gov.uk/releases/thefeasibilityofmeasuringthesharingeconomyprogressupd ate, accessed 12/09/2017.

Office for National Statistics (2017), The Feasibility of Measuring the Sharing Economy. November 2017 Progress Update, https://www.ons.gov.uk/economy/economicoutputandproductivity/output/articles/thefeas ibilityofmeasuringthesharingeconomy/november2017progressupdate accessed 31 January 2019.

Office for National Statistics (2018), Internet Access: Households and individuals. [Available online at:

https://www.ons.gov.uk/peoplepopulationandcommunity/householdcharacteristics/homei nternetandsocialmediausage/datasets/internetaccesshouseholdsandindividualsreferenceta bles, accessed 15/8/18].

Olson, M.J. and S.J. Kemp (2015), Sharing Economy: An In-Depth Look at its Evolution and its Trajectories across Industries. (Minneapolis; MN: Piper Jaffray Investment Research). [Available online at: http://collaborativeeconomy.com/research/sharing-economy-an-indepth-look-at-its-evolution-and-trajectory-across-industries/ accessed 12/09/2017].

Organisation for Economic Cooperation and Development (OECD) (2016), Working Party on Measurement and Analysis of the Digital Economy: New Forms of Work in the Digital Economy. (Paris: OECD).

PricewatershouseCoopers (2014), 'Five Key Sharing Economy Sectors Could Generate 19 billion of UK Revenues by 2025.' [Available online at:

http://pwc.blogs.com/press room/2014/08/five-key-sharing-economy-sectors-couldgenerate-9-billion-of-uk-revenues-by-2025.html, accessed 12/09/2017].

PricewaterhouseCoopers (2015), The Sharing Economy: Consumer Intelligence Series. (Delaware: PricewaterhouseCoopers).

Proserpio, D. and G. Tellis (2017), 'Baring the Sharing Economy: Concepts, Classifications, Findings and Future Directions'. [Available at SSRN: https://ssrn.com/abstract=3084329, accessed on $16 / 8 / 18]$.

Saunders, M. N. K. (2012), 'Choosing research participants', in G. Symon and C. Cassell eds, The practice of qualitative organizational research: Core methods and current challenges (London, UK: Sage), 37-55. 
Schor, J. (2014), Debating the Sharing Economy. (Boston, MA: The Great Transition Initiative).

Schor, J. and C.J. Fitzmaurice (2015), 'Collaborating and Connecting: The Emergence of the Sharing Economy', in L. Resich and J. Thogersen, eds, Handbook on Research on Sustainable Comparison, (Cheltenham: Edward Elgar).

Schor, J.B. et al. (2015), 'On the Sharing Economy', Contexts, 14 (1), 12-19.

Slee, T. (2016), What's Yours is Mine: Against the Sharing Economy. (New York; London: OR Books).

Statistics Canada (2017), The Sharing Economy in Canada. [Available online at:

http://www.statcan.gc.ca/daily-quotidien/170228/dq170228b-eng.htm, accessed 12/09/2017].

Stephany, A. (2015), The Business of Sharing: Making it in the New Sharing Economy. (London: Palgrave Macmillan).

Stokes, K. et al. (2014), Making Sense of the UK Collaborative Economy. (London:

Collaborative Lab/Nesta). [Available online at:

http://www.nesta.org.uk/sites/default/files/making sense of the uk collaborative econo my 14.pdf, accessed 12/09/2017].

Taylor, M.(2016), Independent Review of Employment Practices in the Modern Economy, October 2016. [Available online at: https://www.gov.uk/government/groups/employmentpractices-in-the-modern-economy, accessed on 16/8/18].

Telles Jr. R. (June 2016), Digital Matching Firms: A New Definition in the "Sharing Economy" Space (US Department of Commerce: Economic and Statistics Administration, Office of the Chief Economist), ESA Issue Brief,1(16).

UK Government (2015), Independent Review of the Sharing Economy: Government Response (London: UK Government, Department for Business, Innovation and Skills).

Wosskow, D. (2014), Unlocking the Sharing Economy: An Independent Review (London: UK Government) [Available online at:

https://www.gov.uk/government/uploads/system/uploads/attachment data/file/378291/b is-14-1227-unlocking-the-sharing-economy-an-independent-review.pdf, accessed 12/09/2017].

Zervas, G. et al. (2014), 'The Rise of the Sharing Economy: Estimating the Impact of Airbnb on the Hotel Industry', Boston University School of Management Research Paper Series No. 2013-16 (Boston, MA: Boston University). 